\title{
ACTORS' AND ACTRESSES' PERCEPTIONS ON THE APPLICATIONS OF DISCOURSE ANALYSIS FROM A QUALITATIVE AND QUANTITATIVE OUTLOOK TO MUSICAL THEATRE
}

\author{
PERCEPCIÓN ACTORAL DE LAS APLICACIONES DEL ANÁLISIS DEL \\ DISCURSO DESDE UNA ÓPTICA CUANTITATIVA Y CUALITATIVA \\ AL TEATRO MUSICAL
}

\author{
Antonio Jesús Tinedo RodRíguez \\ Universidad Nacional de Educación a Distancia (UNED) \\ ajtinedo@flog.uned.es
}

Fecha de recepción: 03-06-2021

Fecha de aceptación: 17-09-2021

\section{AbStRaCT}

Homo loquens has the ability of language. Language is present in all the aspects of life, including performing arts. The main goal of this proposal is to assess the perception of actors and actresses on a resource which has been developed to help them make the most of the text; the fundaments of this resource are in the linguistic theory. The main goal of this acting resource which combines a quantitative and a qualitative approach to the text is to foster critical thinking. The goal is thus to approach the dramatic text from different perspectives to provoke deep reflections on the text through discourse analysis. Subsidiarily, an interview to a professional actress has been carried out to know her thoughts on the resource and her perception was positive. As a conclusion, it might be interesting to explore the relationships between drama and linguistics.

KEY WORDS: discourse analysis; performing arts; quantitative methods; politeness; pragmatics 


\section{RESUMEN}

El homo loquens se caracteriza por tener una capacidad diferencial, el lenguaje. El lenguaje impregna todos los ámbitos de la vida, y el arte no es ajeno a este hecho. El objetivo de esta propuesta es evaluar la percepción actoral sobre un recurso para la interpretación de textos basado en la teoría lingüística. Este recurso tiene como objetivo provocar la reflexión del intérprete mediante la combinación de un análisis cuantitativo y cualitativo de un texto dramático. El objetivo es tratar el texto desde múltiples perspectivas para provocar una reflexión profunda sobre el texto dramático a través del análisis discursivo. Se ha realizado una entrevista a una actriz profesional para valorar el recurso y la percepción ha sido positiva. A modo de conclusión, se considera de interés explorar las relaciones con el arte dramático para que la teoría lingüística trascienda y facilite el trabajo actoral.

Palabras clave: Análisis del Discurso; Artes Escénicas; Métodos Cuantitativos; Cortesía; Pragmática

\section{INTRODUCTION}

Exploring symbiotic relationships between different disciplines might result an enriching task. Musical theatre is an interdisciplinary discipline itself because playing a role in a musical comedy usually involved singing, dancing, and acting. This combination is highly demanding because actors and actresses have to prepare their roles thoroughly by integrating their skills in the aforementioned disciplines.

The main goal of this proposal is to provide actors and actresses with a resource which may help them study and analyse dramatic texts by combining a qualitative and a quantitative approach. To exemplify this acting resource, an excerpt retrieved from Mamma Mia! has been analysed under the light of this hybrid method that combines qualitative and quantitative information. The reader may use the formerly mentioned analysis as a guide, but it is important to emphasise that her or his analysis of the same text might be different because cognition is crucial factor when it comes to understand a text in its context. It is not important then to get to the same conclusions nor results, but to consider that it might be a way of approaching a dramatic text.

Even though a holistic and inclusive approach on politeness that takes a set of pragmatic theories into account has been crucial to develop the paper, it is important to highlight that the theories by Sperber \& Wilson ([1986] 1996) and Brown \& Levinson (1987) are at the very core of this proposal. The first one by Sperber \& Wilson ([1986] 1996) is known is a Relevance Theory whilst the second one by Brown \& Levinson (1987) focuses on the concepts of politeness and face.

Dramatic texts are dialogues mainly and it is important to analyse them bearing in mind the concept of face by Goffman (1967) because it helps understand the feelings of the character and then, it is a resource for playing and studying the character. When actors and actresses have to play a character, they should not only take their character into account, but they have to consider the set of relationships among all the characters into account to 
really understand why her or his character behaves in a particular way. The goal then is to uncover the unwritten sociogram behind the play. The theory by Brown \& Levinson (1987) is narrowly linked to Goffman's (1967) concept of face because through that theory a person can deduce when his or her face is being threatened. The theory by Sperber \& Wilson ([1986] 1996) focuses on the relevance of what is being said and it helps analyse the mental representation of the speaker, which in this case is the character which will be played by an actor or an actress.

\section{THEORETICAL FRAMEWORK}

When we analyse the literature on Pragmatics, there are many approaches to the concept of politeness, but the social-norm view is of high interest for this study because it allows to study how is the relationship among the characters of a theatre. Discovering this set of relationships might be of great help for the actor or for the actress because it might provide him or her with better understanding of the whole work and it may have a positive impact on her or his performance.

As it has been mentioned in the first section, the face-saving view is important when it comes to analysing dramatic texts because it helps the actors and actresses understand the scenes and dialogues in which the face of their character is being threatened. Therefore, it is crucial to define what the concept of «face» means in the field of Pragmatics. Goffman (1967:5) was probably one of the pioneers in approaching this concept; the author defined it as «an image of self-delineated in terms of approved social attributes». For Goffman (1967: 9), losing face means «to be out of face» and saving face consists of «a process by which the person sustains an impression for others that he has not lost his face». This theory seems to be the basis of the work developed by Brown \& Levinson (1987).

The positive face consists of the desire of being accepted by other whilst the negative face is narrowly linked to individual rights and freedom. An example of neglection of the positive face would be the criticism towards a piece of art by a painter whilst an example of neglection of the negative face would be the interruption of someone's speech during a conversation. Alba-Juez \& Mackenzie (2016) pointed out that the problem comes when there is a conflict between one's wants, and other people's wants It means that a speech act can become a threat to maintain one's positive or negative face; these are FTAs. For example, let us suppose there are two politicians (politician A and politician B) and they are the leaders of different parties. Let's imagine they have the following conversation:

Politician A: Mrs. B, don't you realise that your policies on economy are not adequate for the country? Unemployment is exponentially decreasing.

Politician B: Mr. A, I think it is by far more constructive providing the chamber with ideas than being always complaining.

In this case A threats B because he criticises the policies of the B party; there is a conflict between his wants and the B party wants and it happens the same with regards to 
speaker B since she accuses Mr. A of his constant complains and his lack of collaboration. Both, Mr. A and Mrs. B threat each other's face.

According to Brown \& Levinson (1987), there are different strategies of politeness linked to Face Threatening Acts. In general terms, the possibility of carrying out a Face Threatening Act is closely related to which extent one's face has been threatened. It is important to highlight that when it comes to analysing dramatic text, inferring the possibility of carrying out is not that important because the play is written, and the author has taken the decisions. Nonetheless, the importance lies on understanding the reasons that motivated that decisions because they might be useful when it comes to choosing different performance strategies such as choosing body language in a particular way. For example, if someone's face is being threatened, it would not be understandable for the audience that the actor or actress that plays the character be smiling. In other words, body language should match the situation.

Besides, it is also important to take the sociological variables into account since they are closely linked to the degree of the Face Threatening Act. Brown \& Levinson (1987) stablished three main sociological variables that are context-dependent; they are distance, power, and rank. Distance is linked to the social distance between the hearer and the speaker; if someone is a relative this value will be probably low (even though it does not have to) whilst if you do not have a close relationship with that person, the value will be higher. The authors do not calculate it quantitatively, but the main innovation of this paper is to assign a numerical value ranging from $\mathrm{X}$ to $\mathrm{Y}^{1}$ to the value to the relationship between every character of the theatre play to create a scale of relationships. The proposed scale is a discrete polytomous scale which should contain Y levels.

In the case of the text that will be analysed, a scale with three levels has been designed. Note that this scale has been developed ad hoc for the text which will be studied in this paper because the types of relationships are clearly defined. The design of the scale and the levels it may contain are subjective elements because each play might require a different scale to reflect the nuances of the relationships of the characters. Theatre plays which are more complex may require a different scale with a wider range of values. When designing that scale, it is important to take into account that the higher the number, the stronger the relationship between these two characters is. It means, the relationship between the numeric value and the strength of the relationship should be directly proportional. This variable is contextual due to the fact that it may change along the story, so it should be assessed for every scene.

Berry, Drmac, \& Jessup (1999) highlight the importance of matrices and vectors (arrays) in the field of information analysis and retrieval. Matrices allow to organise information in rows $(\mathrm{M})$ and columns $(\mathrm{N})$. The dimension of the matrix is $\mathrm{MxN}$. The proposal is to create a D-matrix of to display the information of the formerly mentioned variable. Each character should be placed in a row and in a column. The mathematical representation of this matrix would be $D-$ matrix $=\left(d_{i j}\right) \in \mathbb{N}^{n x m}$. The particularity is

\footnotetext{
$1 \quad X \in \mathbb{N}$ and $Y \in \mathbb{N}$.
} 
that in this case the number of rows and columns is the same, so the D-matrix has the particularity that is a square matrix. It is important to note that all the elements of the matrix $d_{i j}$, which convey the relationship between the character $\langle\mathrm{i} »$ and the character $\langle\mathrm{j} »$, are natural numbers because these numbers should be in accordance with the scale we have previously created. One of the particularities of the matrix is that the diagonal array should be fulfilled by zeros. The reason for that is that we cannot measure the distance between a character and himself or herself, because it does not make sense. Note that the information is quantitative, but it requires a deep analysis of the theatre play, and cognition is clearly involved during the elaboration of a scale matrix that assesses the relationships of distance among characters. The usefulness of this tool does not lie in the quantitative aspect itself, but in the process that actors and actresses have to undergo to create such a matrix. This process is expected to help them gain a deeper understanding on the whole theatre play in general and on the character, they have to play in particular.

Power $(\mathrm{P})$ is another discrete polytomous variable used to express to which an extent the speaker has power over the hearer. It changes because it is contextual and depends on former actions. A speaker can have power over the hearer in a specific moment, but this situation can vary because of different factors. The proposal is to create a P-matrix, $\mathrm{P}-$ matrix $=\left(p_{i j}\right) \in \mathbb{N}^{n x m}$.

Rank (R) is another cultural-dependant discrete polytomous variable and it is linked to the imposition of the speaker over the hearer. The cultural context of production of the theatre play should be borne in mind when analysing because hierarchy is linked to culture. According to Wintergerst \& McVeigh (2010), hierarchy is a key element when exploring culture. The particularity is that this variable does not explore the relationship between two characters, it aims at discovering the hierarchical position of the character in a particular scene and it affects its mathematical representation because we should use a particular use of matrix, the vector. The vector is a matrix of dimension $1 \mathrm{xM}$, being $\mathrm{M}$ the number of characters. The R-vector is thus unidimensional for it will gather the information of rank for each character. Note that hierarchy or rank may vary over the course of the theatre play.

Apart from analysing politeness, it is also important to provide actors and actresses with other strategies to gain a deeper understanding on their characters. The Theory of Relevance by Sperber \& Wilson ([1986] 1996) is suggested as a good complement to the former analysis because it is narrowly linked to cognition for it implies a deep and inferential analysis of the text. STRYKER (1991) explored the importance of relevance when it comes to analysing the relationship between self-identity and your role in society, and emphasised the importance of cognitivism. Asking actors and actresses to analyse the interventions of each character under the light of the Theory of Relevance is expected to activate cognitive processes that allow them to gain a deep insight of the character they are going to play on the stage. Bloom (1956) distinguished between Higher Order Thinking Skills (HOTS) and Lower Order Thinking Skills (LOTS); this taxonomy was revised by Anderson et al. (2013).

This hybrid approach of discourse analysis is clearly linked to the concept of HOTS by Bloom (1956) due to the fact that actors and actresses are supposed to analyse the 
text, connecting ideas between the quantitative and the qualitative approach. Besides, they are expected to evaluate the contents of the dramatic text by justifying their analysis. Finally, they are supposed to put all this knowledge together when they «build» the inner representation by assembling all the information they have gathered along the process.

Other approaches to politeness like the ones by Brown \& Levinson (1987), Culpeper (1996) and Leech (1983) might also be useful for actors and actresses when it comes to analyse their characters.

The correlation FTAs and Gricean maxims is also interesting for this study since the departure hypothesis is that avoiding an FTA implies breaking a maxim. Nonetheless, it is not always right in the other way round; we are going to discuss specific cases in which FTA are likely to take place. Grice (1975) differentiates four types of maxims: quantity, quality, relation and manner. The author stablished different ways of floating these maxims. For example, with regards to the maxim of quantity, Grice (1975) states that making use of ironies flouts this maxim. The example he used was «X is a fine friend» when the reality was that the speaker was saying that ironically because $\mathrm{X}$ is a terrible friend. The positive face of $X$ is being threatened, and the speaker is making use of off record strategies.

The metaphor exemplified by Grice (1975) as a flouting of the quantity maxim is also an example of carrying out an FTA by flouting a Gricean maxim by making use of off record strategies. Therefore, we can conclude, that flouting a maxim sometimes implies an FTA and several examples have been analysed in the sixth section. Lakoff (1973) apud Alba-Juez \& Mackenzie (2016) also supported the conversational maxim view of politeness by proposing two rules for the pragmatic competence: be clear and be polite. The first one is clearly linked to the maxim of manner since the speaker is supposed to be clear and to avoid obscurity.

Grice's Cooperative Principle seems to be at the basis of Leech's (1983) «Politeness Principle» which stablished six maxims (tact, generosity, approbation, modesty, agreement and sympathy). These maxims are narrowly linked to politeness. For example, «bring me the toast!» is a command, and it is a costly act; consequently, it would be an FTA. Nonetheless, «I promise I would do it for you» is a beneficial act, and therefore, it is not an FTA. It is important to emphasise that a beneficial act like an offer could be an FTA if the offer is unwanted.

The work of Leech is linked to the work of Searle due to their different and opposite approach to pragmatics due to the fact that LEECH conceived pragmatics as principlegoverned discipline whilst Searle conceived pragmatics as a rule-governed discipline (Alba-Juez \& Mackenzie, 20I6). Searle (1975) proposed a taxonomy of speech acts which were classified into: representatives, directives, commissive, expressive and declarations. It is important to highlight that bearing this classification in mind we should also have to take into account that there are indirect speech acts. It means that we expect that a declarative clause be a representative speech acts, but it is not always true. For example, if we say somebody «The door!», the clause type is exclamative, but it does not express an emotion, it expresses a command instead, so it is a directive speech act. This indirectness might also result in flouting a maxim and in an FTA, so all the concepts are related. 
To finish, it is important to mention Culpeper's (1996) framework since he approached the concept of impoliteness and formulated a taxonomy of impoliteness strategies such as bald on record impoliteness, positive impoliteness, negative impoliteness, sarcasm or withhold impoliteness. The author also emphasised the importance of non-verbal communication and its relationship with politeness which was not taken into account in the approach by Brown \& Levinson (1987).

\section{EXAMPLE OF THE PROPOSED ANALYSIS APPLIED TO A SCENE FROM MAMMA MIA!}

First of all, it is crucial to carry out a brief analysis of the relationship of the characters of the theatre play in the particular scene we are dealing with. Mamma Mia! is a two-act musical comedy based on the popular songs by ABBA. It tells the story of Donna Sheridan, a woman who got pregnant when she was a young girl. She never told her daughter the truth about her father because she did not even know who he was. When Sophie, her daughter, was about to get married she discovered Donna's secret diary. She invited her three possible fathers after reading the diary, but she did not tell it to anyone, but to her friends, Ali and Lisa.

When Sophie was celebrating her bachelorette party, Sky was told about the invitations and got angry because Sophie had not told him about that. The dialogue which is going to be analysed takes place at Villa Dona (Kalokairi) after Sophie's bachelorette party.

The chosen scene is the second scene of the second act titled The Courtyard. The choice of that scene has to do with the fact that in that point of the story the relationships are clear, and the sociological analysis of the characters can be carried out. In order to create the P-matrix, it is advisable to prepare a chart with the names of the characters. The actor or the actress is supposed to complete this chart consigning the values for each gap. This value should be in accordance with the scale they had already prepared. In this particular case, the scale was:

- 1 is for characters who have no power on others.

- 2 is for characters who might influence others.

- 3 for characters who have a great influence on the decisions of others.

Table 1. Data for the P-matrix. The values in the table indicate the power of a character (column) over another character (row): 1 (characters with no power), 2 (characters with influence), 3 (characters with great influence).

\begin{tabular}{|l|c|c|c|c|c|c|c|c|}
\hline $\mathrm{P}(\mathrm{H}, \mathrm{S})$ & Donna & Tanya & Rosie & Sophie & Harry & Sky & Barman & Ali \\
\hline Donna & - & 2 & 2 & 3 & 1 & 2 & 2 & 2 \\
\hline Tanya & 2 & - & 2 & 2 & 1 & 2 & 1 & 1 \\
\hline Rosie & 2 & 2 & - & 2 & 1 & 2 & 1 & 1 \\
\hline
\end{tabular}




\begin{tabular}{|l|c|c|c|c|c|c|c|c|}
\hline $\mathrm{P}(\mathrm{H}, \mathrm{S})$ & Donna & Tanya & Rosie & Sophie & Harry & Sky & Barman & Ali \\
\hline Sophie & 3 & 2 & 2 & - & 2 & 3 & 1 & 1 \\
\hline Harry & 1 & 1 & 1 & 2 & - & 3 & 1 & 1 \\
\hline Sky & 2 & 1 & 1 & 3 & 1 & - & 1 & 1 \\
\hline Barman & 1 & 1 & 1 & 1 & 1 & 1 & - & 1 \\
\hline Ali & 1 & 1 & 1 & 2 & 1 & 1 & 1 & - \\
\hline
\end{tabular}

In order to design the P-matrix, the data should be recorded carefully in a table as displayed in Table 1. People from the cast may compare their P-matrices so that they can share their thoughts and learn from their peers. The numbers of the scale should be assigned bearing the plot in mind. For example, Donna, Tanya and Rosie are old friends who have shared special moments. They always give some advice each other and it is where their power lies. The same pattern applies to Ali, Sophie and Lisa. Sophie and Sky are in love and they are going to get married, that is why their score in the scale is the maximum. Donna is Sophie's mother and that is why they also got the maximum punctuation because this type of relationship in the context of the play and in this particular scene is really strong. The punctuation of secondary characters whose relationship with the rest is not relevant is the lower one.

$$
P(H, S)=\left(\begin{array}{llllllll}
0 & 2 & 2 & 3 & 1 & 2 & 2 & 2 \\
2 & 0 & 2 & 2 & 1 & 2 & 1 & 1 \\
2 & 2 & 0 & 2 & 1 & 2 & 1 & 1 \\
2 & 2 & 2 & 0 & 2 & 2 & 1 & 1 \\
1 & 1 & 1 & 2 & 0 & 3 & 1 & 1 \\
2 & 1 & 1 & 2 & 1 & 0 & 1 & 1 \\
1 & 1 & 1 & 1 & 1 & 1 & 0 & 1 \\
1 & 1 & 1 & 2 & 1 & 1 & 1 & 0
\end{array}\right)
$$

The process of designing the D-matrix is similar to the one of the P-matrix. In this case, it is important to take into account that the numbers of the scale are not directly proportional but inversely proportional, because the higher the number is, the lower the distance is.

Table 2. Data for the D-matrix. The values in the table indicate the distance between a character (column) and another character (row): 1 (characters with a short distance), 2 (characters with an average distance), 3 (characters with a great distance).

\begin{tabular}{|l|l|l|l|l|l|l|l|l|}
\hline $\mathrm{D}(\mathrm{H}, \mathrm{S})$ & Donna & Tanya & Rosie & Sophie & Harry & Sky & Barman & Ali \\
\hline Donna & - & 1 & 1 & 1 & 2 & 2 & 3 & 2 \\
\hline Tanya & 1 & - & 1 & 1 & 2 & 1 & 2 & 2 \\
\hline
\end{tabular}




\begin{tabular}{|l|l|l|l|l|l|l|l|l|}
\hline $\mathrm{D}(\mathrm{H}, \mathrm{S})$ & Donna & Tanya & Rosie & Sophie & Harry & Sky & Barman & Ali \\
\hline Rosie & 1 & 1 & - & 1 & 2 & 1 & 3 & 2 \\
\hline Sophie & 1 & 1 & 1 & - & 1 & 1 & 2 & 1 \\
\hline Harry & 2 & 2 & 2 & 1 & - & 3 & 3 & 3 \\
\hline Sky & 2 & 1 & 1 & 1 & 3 & - & 1 & 1 \\
\hline Barman & 3 & 2 & 3 & 2 & 3 & 1 & - & 1 \\
\hline Ali & 2 & 2 & 2 & 1 & 3 & 1 & 1 & - \\
\hline
\end{tabular}

The pair of characters whose value is one have a short distance; it means they have a democratic relationship in which hierarchy is not important. The ones whose value is two have some degree of distance, be it for hierarchy or be it for their biographical data. The ones who have been assigned the number three have a hierarchical relationship or are simply unknowns. For example, Sky is friend of the barman, that is why their punctuation is one as can be observed in Table 2. Nonetheless, the barman works in Donna's hotel, that is why they have such a value in this item. Again, it is important to emphasise that the numbers are not the most relevant part because they are based on perceptions. Therefore, culture and cognition play a key role. Nonetheless, they force actors and actresses to deepen on the sociological relationships among the characters.

The D-matrix consists of the data in Table 2.

$$
D(S, H)=\left(\begin{array}{llllllll}
0 & 1 & 1 & 1 & 2 & 2 & 3 & 2 \\
1 & 0 & 1 & 1 & 2 & 1 & 2 & 2 \\
1 & 1 & 0 & 1 & 2 & 1 & 3 & 2 \\
1 & 1 & 1 & 0 & 1 & 1 & 2 & 1 \\
2 & 2 & 2 & 1 & 0 & 3 & 3 & 3 \\
2 & 1 & 1 & 1 & 3 & 0 & 1 & 1 \\
3 & 2 & 3 & 2 & 3 & 1 & 0 & 1 \\
2 & 2 & 2 & 1 & 3 & 1 & 1 & 0
\end{array}\right)
$$

Designing the R-vector is slightly different due to the fact that now we do not have two entries to explore the relationship between characters, we should think of the rank of the character in the scene, that is why it is a vector and not a matrix, because it just has one entry. Note that the higher the number, the higher the rank.

Table 3. Data for the R-vector. The values indicate the rank of character: 1 (characters with a low rank), 2 (characters with an average rank), 3 (characters with a high rank).

\begin{tabular}{|l|c|c|c|c|c|c|c|c|}
\hline R-vector & Donna & Tanya & Rosie & Sophie & Harry & Sky & Barman & Ali \\
\hline Value & 3 & 2 & 2 & 2 & 2 & 2 & 1 & 1 \\
\hline
\end{tabular}


The resulting vector is:

$$
\vec{r}=\left(\begin{array}{llllllll}
3 & 2 & 2 & 2 & 2 & 2 & 1 & 1
\end{array}\right)
$$

As the reader may observe in Table 3 which contains the values of rank for each character, Donna has the highest rank due to the fact that she is the main character, and all the action goes around her. Besides, in the context of the play, she is the owner of the hotel and has the highest power. The barman is her employee and has little power, that is why he has low rank.

There is a concept of interest in the theory by Brown \& Levinson (1987) which is the concept of weightiness. Weightiness is the addition of power, distance and rank and it is linked to the probability of carrying out an FTA.

$$
W_{x}=D(S, H)+P(H, S)+R x
$$

Hoebe (2001) tested this formula empirically in radio programmes by using a combination of both quantitative and qualitative analyses. According to the results of the author, the formula predicts politeness strategies and the likelihood of performing an FTA. It is important to highlight that the author affirms that the formula works better in longer scenes. Even though it is not the objective of this paper, it is an interesting tool for acting because it helps actors and actresses understand the concept of face in his or her own character.

The theory by Sperber \& Wilson ( [1986] 1996 ) is also of great importance when it comes to completing the former analysis because it is linked with cognition. Internal representations are a crucial in this theory. They have to do with thoughts and memories, and thus with cognition. Approaching the text thoroughly, attempting to create connections between linguistic and paralinguistic elements and carrying out inferences from the text could be a key tool when it comes to performing. Stage directions together with the text are the cognitive input that should be processed by the actor or the actress to gain a deeper and more solid understanding of the character.

Table 4. Conversational turns from the chosen scene.

\begin{tabular}{|c|l|l|}
\hline $\begin{array}{c}\text { Number of } \\
\text { conversational turn }\end{array}$ & \multicolumn{1}{|c|}{ Speaker } & \multicolumn{1}{c|}{ Conversational turn } \\
\hline 1 & Donna & What a mess! Hey! \\
\hline 2 & Sophie & What \\
\hline 3 & Donna & Are you okay? \\
\hline 4 & Sophie & Yes, I'm fine \\
\hline 5 & Donna & Wow, Sophie... \\
\hline 6 & Sophie & What? \\
\hline
\end{tabular}




\begin{tabular}{|c|l|l|}
\hline $\begin{array}{c}\text { Number of } \\
\text { conversational turn }\end{array}$ & Speaker & \multicolumn{1}{c|}{ Conversational turn } \\
\hline 7 & Donna & $\begin{array}{l}\text { Last night, you and Sky... What's wrong? Tell me. } \\
\text { Tell me what's wrong. }\end{array}$ \\
\hline 8 & Sophie & I don't know what to do. \\
\hline 9 & Donna & $\begin{array}{l}\text { You know what to do. You don't have to do } \\
\text { anything. It's not too late, I can still call off the we- } \\
\text { dding. Everybody will understand. }\end{array}$ \\
\hline 10 & Sophie & Call... Call off the wedding? \\
\hline
\end{tabular}

To exemplify what has been mentioned on the Theory of Relevance, we may take conversational turns number 9 and number 10 into account. They can be read in Table 4 which contains ten conversational turns from the chosen scene. Donna receives an input which led her to think that Sophie wants to call off the wedding whilst Sophie inferred that it was Donna who wanted to cancel the wedding. For them both, the input is relevant, and they both have presuppositions. This cognitive work is crucial for the actor or the actress because working with this input also implies an important acting effort because they might create specific memories for their character through the input to reinforce their acting. At the end of the day, it consists of analysing the dramatic text deeply to facilitate the understanding and the interpretation of the text.

Subsidiarily, approaches like the one by Culpeper (1996) and Leech (1983) may reinforce the interpretation of the text, even though the focus in this article has been put in the approaches by Sperber \& Wilson ([1986] 1996) and Brown \& Levinson (1987).

\section{EVALUATION OF THE PROPOSAL}

The main objective of this paper is to introduce a hybrid approach to analyse dramatic texts with the goal of helping actors and actresses to work on their acting bearing linguistics in mind. This approach has been explained in the former section by making use of a text from the musical comedy Mamma mia!

A subsidiary objective was to know the perception of actors and actresses on this new approach. To do so, a professional actress has been interviewed after having been explained the approach. The questions were the following ones:

a) Do you make use of linguistics when you have to perform a character in a theatre play?

b) What do you think of this acting resource that involves a sociological quantitative analysis and a linguistic analysis under the prism of the Theory of Relevance?

c) Do you think politeness and the theory of relevance could improve your acting? 
The interview has been carried out through What's App asynchronously through voice messages. As the mother tongue of the actress is Spanish, the language of the interview was carried out in Spanish.

After analysing the interview, it is important to highlight that the actress affirmed that she had no knowledge on discourse analysis, and she did not apply it explicitly when studying a character. Nonetheless, she finds it interesting because she said it might be a good resource because this approach goes beyond the text; it implies a thorough reflection on the whole dramatic text, and she affirmed reflection is crucial when it comes to performing. She would like that theories on pragmatics and discourse analysis be accessible for actors and actresses because they welcome new resources.

Regarding the second question, she was surprised when she heard about the quantitative approach, but she affirmed she would like to do it because it might provide her with a deeper insight on the libretto. What she liked the most it that this resource is thoughtprovoking.

With regards to her last question, she thinks all the new knowledge is welcome because it provides the actor or the actress with new perspectives on the text.

It is important to highlight that it is not easy to have access to professional actors and actresses and that is why the sample is so reduced, but it provides with some hints of a professional who is constantly studying characters. Nonetheless, it is important to take into account that actors and actresses do not have to be necessarily experts on linguistics, and it can be an important drawback for those who are not familiar with linguistics.

\section{CONCLUSIONS}

As a conclusion, linguistics in general, and discourse analysis in particular, might be of great help to other disciplines such as theatre. Providing actors and actresses with knowledge on linguistics might be helpful for them when studying a new character because their main source of information is the text. They also have secondary sources of information such as recordings, but they are not available for every play and for every character.

This proposal aims at preparing a resource that combines a quantitative and a qualitative approach to the dramatic text to help actors and actresses prepare their characters. The objective of the quantitative approach is not to measure the relationships of the characters in a play but to foster critical thinking and make actors and actresses reflect on the sociology of the literary text to help the understand their character and the play.

The interview with the professional actress shows the need of building bridges between linguistics and other disciplines such as drama because at the end of the day language is crucial for performing arts. Singing, for examples, requires a solid understanding of the lyrics. The singer should find bridges between music theory and linguistic knowledge to sing a song because singing goes beyond producing beautiful sounds with a good 
technique, it is about evoking feelings aesthetically. In order to evoke these feelings, it is crucial to understand deeply the lyrics of the song.

Building bridges may imply finding symbiotic relations among disciplines and it is the real aim of this paper. The objective is to provide actors and actresses with a proposal of acting resource based on the linguistic theory. Future research on this topic may focus on piloting this resource with actors and actresses. Adapting and divulging the knowledge on linguistics is crucial because it enriches other disciplines.

\section{REFERENCES}

Alba-Juez, L. A., \& Mackenzie, L. (2016): Pragmatics: Cognition, Context \& Culture. Madrid, McGraw-Hill, UNED.

Anderson, L., Krathwohl, D., Airasian, P., Cruikshank, K., Mayer, R., Pintrich, P., \& WitтRоск, M. (2013): Taxonomy for Learning, Teaching, and Assessing, A: A Revision of Bloom's Taxonomy of Educational Objectives, New York, Longman .

Berry, M. W., Drmac, Z., \& Jessup, E. R. (1999): «Matrices, Vector Spaces, and Information Retrieval» SIAM Review, 41.2, pp. 335-362.

Bloom, B. (1956): Taxonomy of Educational Objectives, Handbook I: The Cognitive Domain, New York, David McKay Co Inc.

CulpePer, J. (1996): «Towards an Anatomy of Impoliteness», Journal of Pragmatics, 25, pp. 349-367.

Goffman, E. (1967): «On Face Work: An Analysis of Ritual Elements in Social Interaction», Interaction ritual. Essays on Face-to-Face Behaviour, ed. E. Goofman, New York, Pantheon Books, pp. $5-46$.

Hoebe, S. E. (2001): «Predicting Politeness Strategies in English Conversation», ELIA, 2, pp. 181-197.

LeECH, G. N. (1983): Principles of Pragmatics. London, Longman.

Searle, J. R. (1975): «A Taxonomy of Illocutionary Acts», Minessota Studies in the Philosophy of Science, 9, eds. P. Cole, \& J. L. Morgan, pp. 344-396.

Sperber, D., \& Wilson, D. ([1986] 1996): Relevance: Communication and Cognition, Cambridge, Wiley-Blackwell.

STRYKER, S. (1991): «Exploring the Relevance of Social Cognition for the Relationship of Self and Society: Linking the Cognitive Perspective and Identity Theory», The Self-Society Dynamic: Cognition, Emotion and Action, eds. J. A. Howard, \& P. L. Callero, Cambridge: Cambridge University Press, pp. 19-42.

Wintergerst, A., \& McVeIgh, J. (2010): Tips for Teaching Culture: Practical Approaches to Intercultural Communication, New York, Pearson Longman. 